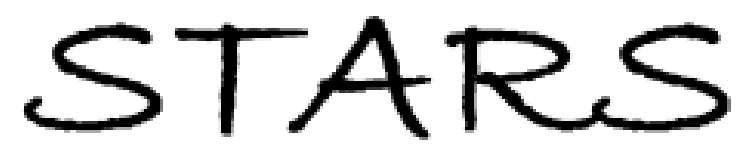

University of Central Florida

STARS

$1-1-2010$

\title{
Low temperature deformation of the R-phase in a NiTiFe shape memory alloy
}

\author{
V. B. Krishnan \\ University of Central Florida \\ S. B. Shmalo \\ University of Central Florida \\ C. R. Rathod \\ University of Central Florida \\ M. A. M. Bourke \\ R. Vaidyanathan \\ University of Central Florida
}

Find similar works at: https://stars.library.ucf.edu/facultybib2010

University of Central Florida Libraries http://library.ucf.edu

This Article is brought to you for free and open access by the Faculty Bibliography at STARS. It has been accepted for inclusion in Faculty Bibliography 2010 s by an authorized administrator of STARS. For more information, please contactSTARS@ucf.edu.

\section{Recommended Citation}

Krishnan, V. B.; Shmalo, S. B.; Rathod, C. R.; Bourke, M. A. M.; and Vaidyanathan, R., "Low temperature deformation of the R-phase in a NiTiFe shape memory alloy" (2010). Faculty Bibliography 2010s. 388. https://stars.library.ucf.edu/facultybib2010/388

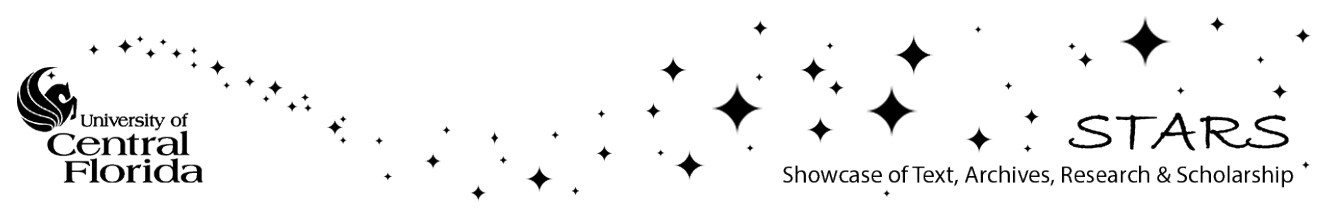




\section{Low temperature deformation of the R- phase in a NiTiFe shape memory alloy}

Cite as: Appl. Phys. Lett. 97, 091910 (2010); https://doi.org/10.1063/1.3481694

Submitted: 16 February 2010 . Accepted: 03 August 2010 . Published Online: 03 September 2010

V. B. Krishnan, S. B. Shmalo, C. R. Rathod, M. A. M. Bourke, and R. Vaidyanathan

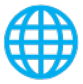

\section{ARTICLES YOU MAY BE INTERESTED IN}

A Low Hysteresis NiTiFe Shape Memory Alloy Based Thermal Conduction Switch AIP Conference Proceedings 824, 3 (2006); https://doi.org/10.1063/1.2192327

Elastocaloric effect in a textured polycrystalline Ni-Mn-In-Co metamagnetic shape memory alloy

Applied Physics Letters 105, 161905 (2014); https://doi.org/10.1063/1.4899147

High cyclic stability of the elastocaloric effect in sputtered TiNiCu shape memory films Applied Physics Letters 101, 091903 (2012); https://doi.org/10.1063/1.4748307

\section{Applied Physics Reviews} Now accepting original research 


\title{
Low temperature deformation of the R-phase in a NiTiFe shape memory alloy
}

\author{
V. B. Krishnan, ${ }^{1}$ S. B. Shmalo, ${ }^{1}$ C. R. Rathod, ${ }^{1}$ M. A. M. Bourke ${ }^{2}$ and R. Vaidyanathan ${ }^{1, a)}$ \\ ${ }^{1}$ Department of Mechanical, Materials and Aerospace Engineering, Advanced Materials Processing \\ and Analysis Center (AMPAC), University of Central Florida, Orlando, Florida 32816, USA \\ ${ }^{2}$ Los Alamos National Laboratory, Los Alamos, New Mexico 87545, USA
}

(Received 16 February 2010; accepted 3 August 2010; published online 3 September 2010)

\begin{abstract}
Deformation in the $P 3$ phase (R-phase) of NiTiFe was investigated by in situ neutron diffraction during compressive loading at cryogenic temperatures. At $216 \mathrm{~K}$, upon loading the R-phase detwinned and subsequently underwent a reversible stress-induced transformation to the $B 19^{\prime}$ phase (martensite). At $92 \mathrm{~K}$ on the other hand, detwinning was suppressed and the stress-induced martensite formed did not transform back upon unloading. The experiments also directly observed a hitherto theoretically predicted $B 33$ phase. Rietveld refinement of the neutron diffraction spectra were used to determine lattice parameters of the $B 33$ and R-phases. Plane-specific elastic moduli were also determined for the R-phase. (C) 2010 American Institute of Physics.
\end{abstract}

[doi:10.1063/1.3481694]

NiTiFe shape memory alloys are known to exhibit temperature and/or stress-induced phase transformations between cubic $B 2$, trigonal $P 3$, and monoclinic $B 19^{\prime}$ phases (commonly designated as austenite, R-phase, and martensite, respectively). The R-phase and martensite have the ability to detwin and convert between their respective variants when deformed (phenomena commonly referred to as detwinning). ${ }^{1,2}$ For example, cooling a NiTiFe alloy that is austenitic at room temperature can result in a phase transformation to the R-phase which can subsequently be deformed to detwin and/or form stress-induced martensite. The reverse transformation from detwinned R-phase can occur against external loads below room temperature making these alloys useful as actuators, e.g., in low temperature thermal switches. The R-phase transformation in NiTiFe is of particular interest owing to its stability and reduced hysteresis. ${ }^{3,4}$ Macroscopic measurements cannot differentiate between elastic and inelastic strains associated with detwinning or stress-induced transformation. Therefore, knowledge on deformation in the R-phase is currently limited especially with respect to its elastic behavior and the competition between detwinning and the formation of stress-induced martensite. Furthermore, the reversibility of the R-phase transformation to martensite and the formation of any additional stress-induced phases have not been investigated.

With the objective of providing insight into the aforementioned issues, in situ neutron diffraction during cooling and mechanical loading was performed on a NiTiFe sample at the spallation neutron source at Los Alamos National Laboratory. This technique has previously provided valuable insight into the strain, texture, and phase fraction evolution in bulk shape memory alloy specimens (e.g., Refs. 5-7). However, the capability to perform in situ neutron diffraction during loading and cooling has only recently been implemented. ${ }^{8}$ Here it was used to make in situ neutron diffraction experiments on a $\mathrm{Ni}_{46.8} \mathrm{Ti}_{50} \mathrm{Fe}_{3.2}$ alloy at a minimum temperature of $92 \mathrm{~K}$ and a maximum compressive stress of $700 \mathrm{MPa}$.

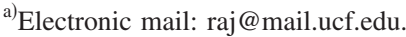

Cylindrical compression samples $(10 \mathrm{~mm}$ in diameter and $24 \mathrm{~mm}$ length) were fabricated by electrical discharge machining from a vacuum-induction-melted and vacuumarc-remelted billet. The samples were solutionized at $1023 \mathrm{~K}$ for $1 \mathrm{~h}$ in a vacuum furnace and subsequently oil quenched to room temperature. The R-phase start, R-phase finish, austenite start, and austenite finish, were determined by differential scanning calorimetry to be $236 \mathrm{~K}, 223 \mathrm{~K}, 227 \mathrm{~K}$, and $239 \pm 2 \mathrm{~K}$, respectively. The martensite start temperature was undetectable while cooling the sample to $20 \mathrm{~K}$. Measurements were performed in "time-of-flight" mode using the capability for neutron diffraction during cooling and mechanical loading on the Spectrometer for Materials Research at Temperature and Stress (Ref. 9) at Los Alamos National Laboratory. Measurements were made on two samples. One sample was cooled to $216 \mathrm{~K}$ and mechanically loaded and unloaded to a maximum stress of $700 \mathrm{MPa}$ while neutron spectra were recorded at selected stresses. A second identical sample was cooled to $92 \mathrm{~K}$ and mechanically loaded and unloaded to a maximum stress of $420 \mathrm{MPa}$ while neutron spectra were again acquired at selected stresses.

Upon cooling from room temperature both samples underwent a phase transformation from austenite to R-phase. Figure 1 shows a section of neutron spectra obtained from the samples at 300,216 , and $92 \mathrm{~K}$ in the nominally unloaded condition (holding stress of $8 \mathrm{MPa}$ ). At $300 \mathrm{~K}$, the $\{110\}$ austenitic peak is seen which subsequently split with cooling to $\{300\}$ and $\{112\}$ R-phase peaks as a result of elongation along the $\langle 111\rangle$ crystallographic direction of the $B 2$ phase. $^{10}$ The splitting increased with cooling due to a change in the trigonal angle of the R-phase unit cell. ${ }^{11}$ Similarly, splitting of the austenite $\{210\}$ peak to R-phase $\{303\}$ and $\{411\}$ peaks were observed. The peaks were identified based on a $=3.0112 \pm 0.0002 \AA$ for the cubic austenite phase at $300 \mathrm{~K}$ and $\mathrm{a}=\mathrm{b}=7.3004 \mathrm{c}=5.2878( \pm 0.0002 \AA)$ for the trigonal $\mathrm{R}$-phase at $92 \mathrm{~K}$ in the unloaded condition (as determined by Rietveld refinement of neutron spectra ${ }^{12}$ ).

Compressive loading of the R-phase at 216 and $92 \mathrm{~K}$ produced different results. On examining a section of neutron spectra corresponding to $\{111\}$ R-phase and $\{011\}$ mar- 


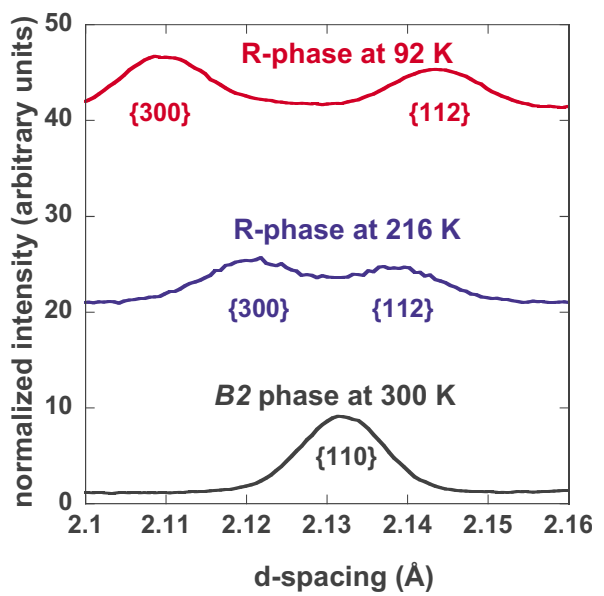

FIG. 1. (Color online) Section of normalized neutron diffraction spectra acquired at $300 \mathrm{~K}, 216 \mathrm{~K}$, and $92 \mathrm{~K}$, respectively, showing phase transformation from cubic austenite (B2) to trigonal R-phase in NiTiFe. The reflections are from lattice planes perpendicular to the length of the sample.

tensite peaks acquired during loading and unloading up to $700 \mathrm{MPa}$ at $216 \mathrm{~K}$ in Fig. 2(a), a stress-induced R-phase to martensite phase transformation was observed during loading as the $\{111\} \mathrm{R}$-phase peak decreased in intensity and the
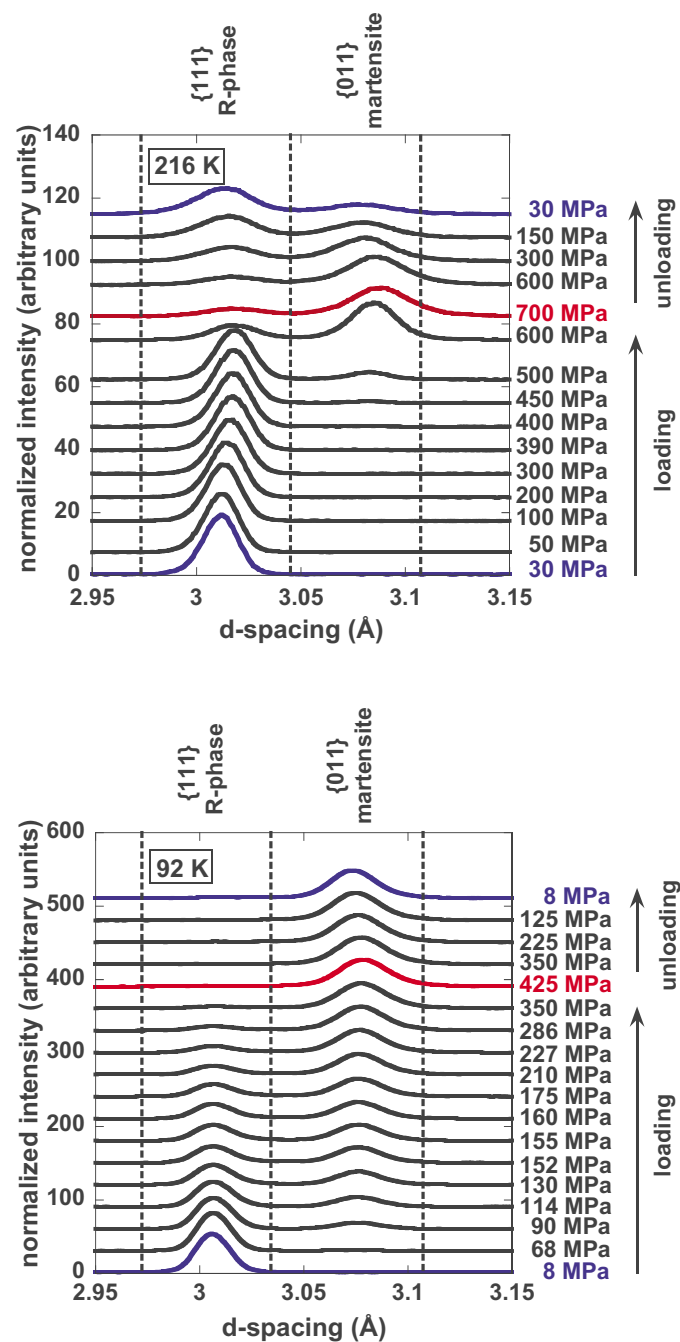

FIG. 2. (Color online) Section of normalized neutron diffraction spectra acquired during loading and unloading at (a) 216 and (b) $92 \mathrm{~K}$ in NiTiFe. At $216 \mathrm{~K}$ the R-phase reversed from martensite upon unloading but not at $92 \mathrm{~K}$. The reflections are from lattice planes perpendicular to the length of the sample.
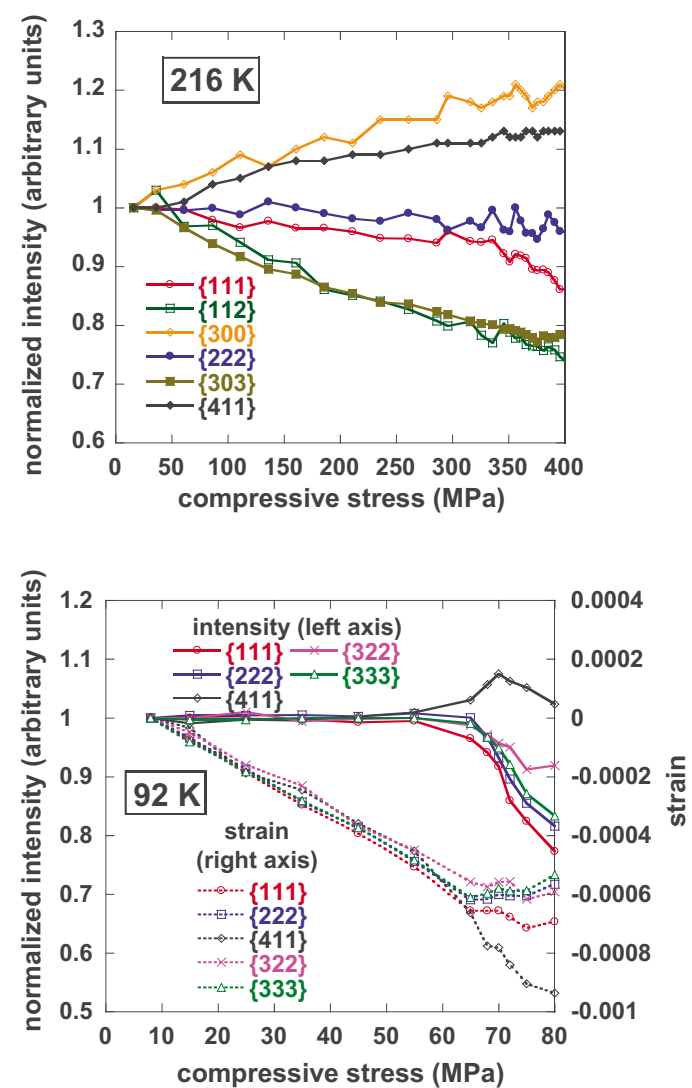

FIG. 3. (Color online) The solid lines are the normalized R-phase peak intensity ratios (relative to the unloaded state) with loading at (a) 216 and (b) $92 \mathrm{~K}$. The dashed lines in (b) are the strains determined from changes in d-spacing of various R-phase reflections at $92 \mathrm{~K}$. The reflections in (a) are from lattice planes parallel and in (b) perpendicular to the length of the sample and are, respectively, selected for clarity and in order to determine plane-specific moduli.

$\{011\}$ martensite peak increased in intensity. Upon unloading, the martensite reverted to the R-phase as seen in the reverse trend in the $\{111\}$ R-phase and $\{011\}$ martensite peaks. In contrast, for the sample cooled to $92 \mathrm{~K}$, the stress-induced martensite formed from R-phase upon loading remained in the nominally unloaded condition [Fig. 2(b)]. This difference in behavior between testing at 216 and $92 \mathrm{~K}$ is attributed to the thermodynamic hysteresis typically associated with martensitic transformations wherein the reverse transformation to R-phase from martensite occurs at higher temperatures (higher than $92 \mathrm{~K}$ in this case). ${ }^{13}$ Furthermore, as expected thermodynamically, martensite is favored at lower temperatures resulting in stress-induced martensite forming at around $65 \mathrm{MPa}$ at $92 \mathrm{~K}$ and at around $450 \mathrm{MPa}$ at $216 \mathrm{~K}$.

The solid lines in Figs. 3(a) and 3(b) are presented to investigate detwinning in the R-phase and correspond to the ratio of normalized intensities of individual $\mathrm{R}$-phase diffraction peaks with respect to the unloaded state. The information is presented for peaks selected for the statistical quality of their fits as previously established during the analysis of neutron diffraction spectra acquired in situ during loading in NiTi. ${ }^{12}$ The observation that certain reflections increase in normalized intensity with loading and certain reflections decrease in normalized intensity with loading up to $400 \mathrm{MPa}$ at $216 \mathrm{~K}$ [Fig. 3(a)] is indicative of texture evolution associated with detwinning in the R-phase at $216 \mathrm{~K}$. In contrast, Fig. 3(b) which represents deformation in the R-phase at $92 \mathrm{~K}$ does not show this trend and the intensities remained around 


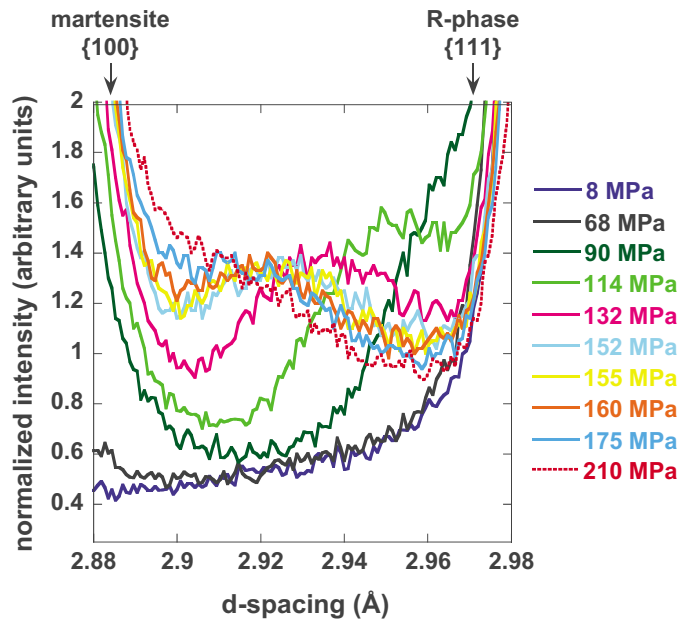

FIG. 4. (Color online) Section of normalized neutron diffraction spectra acquired at $92 \mathrm{~K}$ during loading, showing stress-induced phase transformation from R-phase to $B 19^{\prime}$ martensite. The $\{012\}$ peak of an hitherto theoretically predicted $B 33$ martensite is observed.

the normalized valued of unity until about $65 \mathrm{MPa}$. At stresses higher than $65 \mathrm{MPa}$, the R-phase underwent a stressinduced transformation to martensite, and hence a decrease in the normalized intensities of the various reflections was observed. Thus at $216 \mathrm{~K}$ and at stresses below $500 \mathrm{MPa}$, the free energy of the R-phase is lower than that of the monoclinic phase and hence detwinning is favored as the deformation mode to accommodate stress. However, at stresses above $500 \mathrm{MPa}$ the system lowers its energy by undergoing a stress-induced transformation to martensite, which reverts to the R-phase upon unloading [Fig. 2(a)]. At $92 \mathrm{~K}$ on the other hand, detwinning is suppressed and a direct stressinduced transformation to martensite is observed that does not revert due to the thermal hysteresis associated with martensitic transformations. The fact that detwinning is limited at stresses lower than $65 \mathrm{MPa}$ at $92 \mathrm{~K}$ enabled the comparison of the macroscopic modulus determined from extensometry with the plane-specific elastic moduli determined from changes in d-spacing (relative to a stress free d-spacing) with stress. ${ }^{12}$ The dashed lines in Fig. 3(b) represent these strains with increasing stress for various R-phase planes. The modulus from extensometry was determined to be $90.9 \mathrm{GPa}$ and compared well with the values of $95.6 \mathrm{GPa}, 113.8 \mathrm{GPa}$, and 105.2 GPa for the $\{111\},\{322\}$, and $\{411\}$ planes, respectively. At stresses above $65 \mathrm{MPa}$, the onset of stress-induced transformation results in redistribution of strain among various grains resulting in a nonlinear and anisotropic response. ${ }^{7,12}$

Figure 4 shows a section of neutron spectra recorded from the sample at $92 \mathrm{~K}$ as it is loaded from the nominally unloaded condition (8 MPa) to $210 \mathrm{MPa}$. The spectra have been normalized and are overlaid. The maximum value of the $x$-axis corresponds to that of the d-spacing of the $\{111\}$ $\mathrm{R}$-phase peak on the right and the minimum value to that of the $\{100\}$ martensite peak on the left. As the sample is loaded a peak appears in the middle and shifts with stress. The shift if hypothetically attributed to elastic straining due to applied stress results in an unrealistic modulus of $6.3 \mathrm{GPa}$. The position of this reflection is consistent with that of the $\{012\}$ reflection in a base-centered orthorhombic B33 NiTi structure (space group $\mathrm{Cmcm}$ ) predicted from density functional theory calculations. ${ }^{14}$ This structure does not possess a unique crystallographic relationship with the parent phase and is expected to only exist in the absence of shear and hydrostatic stresses (applied or residual). The experimentally observed shifting is thus attributed to a change in the monoclinic angle to $\gamma \approx 98^{\circ}$ as the symmetry changes from $B 33$ to that of $B 19^{\prime}$ with stress. Rietveld refinement of the acquired spectra resulted in the following lattice parameters for the $B 33$ phase: $\mathrm{a}=2.911, \mathrm{~b}=9.393, \mathrm{c}=3.806$, and $( \pm 0.001 \AA)$ $\alpha=\beta=\gamma=90^{\circ}$ which compared well with the aforementioned theoretical predictions.

In summary, by recourse to capability of neutron diffraction during loading at cryogenic temperatures at a spallation neutron source insight is provided into deformation in the trigonal R-phase in bulk shape memory NiTiFe. At $216 \mathrm{~K}$, there is direct evidence of detwinning in the R-phase followed by a reversible stress-induced martensitic transformation as the R-phase transforms to martensite and transforms back upon unloading. At $92 \mathrm{~K}$, however, detwinning is suppressed and the stress-induced martensite formed does not revert to the R-phase due to hysteresis in the transformation. The elastic modulus of the R-phase from atomic measurements was consistent with that from extensometry. A nascent peak was observed during loading of the R-phase at $92 \mathrm{~K}$ that shifted with loading and was attributed to that of the $B 33$ martensite, a phase that hitherto has only been predicted in theory. These findings have practical implications for using the R-phase in cryogenic actuator applications, wherein a limiting temperature exists below which detwinning is suppressed in the R-phase (as was seen here at $92 \mathrm{~K}$ ), thereby not providing recoverable strains necessary for the alloy to exhibit shape memory behavior.

R.V. acknowledges funding from NSF (CAREER under Grant No. DMR-0239512), NASA (Grant No. NAG3-2751) and SRI. The authors thank B. Clausen, D. Brown, and T. Sisneros at LANL for experimental assistance. This work has benefited from the use of the Lujan Neutron Scattering Center at LANSCE, which is funded by the Office of Basic Energy Sciences (DOE). LANL is operated by Los Alamos National Security LLC under DOE Contract No. DE-AC5206NA25396.

${ }^{1}$ K. Otsuka and X. Ren, Prog. Mater. Sci. 50, 511 (2005).

${ }^{2}$ V. B. Krishnan, R. M. Manjeri, B. Clausen, D. W. Brown, and R. Vaidyanathan, Mater. Sci. Eng., A 481-482, 3 (2008).

${ }^{3}$ J. L. Lemanski, V. B. Krishnan, R. Mahadevan Manjeri, W. U. Notardonato, and R. Vaidyanathan, Adv. Cryog. Eng. 52A, 3 (2006).

${ }^{4}$ V. B. Krishnan, C. Bewerse, W. U. Notardonato, and R. Vaidyanathan, Adv. Cryog. Eng. 54, 3 (2008).

${ }^{5}$ S. Rajagopalan, A. L. Little, M. A. M. Bourke, and R. Vaidyanathan, Appl. Phys. Lett. 86, 081901 (2005).

${ }^{6}$ C. R. Rathod, B. Clausen, M. A. M. Bourke, and R. Vaidyanathan, Appl. Phys. Lett. 88, 201919 (2006).

${ }^{7}$ S. Qiu, V. B. Krishnan, S. A. Padula II, R. D. Noebe, D. W. Brown, B. Clausen, and R. Vaidyanathan, Appl. Phys. Lett. 95, 141906 (2009).

${ }^{8}$ T. R. Woodruff, V. B. Krishnan, B. Clausen, T. Sisneros, V. Livescu, D. W. Brown, M. A. M. Bourke, and R. Vaidyanathan, Rev. Sci. Instrum. 81, 063903 (2010).

${ }^{9}$ M. A. M. Bourke, D. C. Dunand, and E. Ustundag, Appl. Phys. A: Mater. Sci. Process. 74, s1707 (2002).

${ }^{10}$ T. Goryczka and H. Morawiec, J. Alloys Compd. 367, 137 (2004).

${ }^{11}$ K. F. Hane and T. W. Shield, Mater. Sci. Eng., A 291, 147 (2000).

${ }^{12}$ R. Vaidyanathan, M. A. M. Bourke, and D. C. Dunand, J. Appl. Phys. 86, 3020 (1999).

${ }^{13}$ R. J. Salzbrenner and M. Cohen, Acta Metall. 27, 739 (1979).

${ }^{14}$ X. Huang, G. J. Ackland, and K. M. Rabe, Nature Mater. 2, 307 (2003). 